\title{
Surface Thermolytic Behavior of Nickel Amidinate and Its Implication on the Atomic Layer Deposition of Nickel Compounds
}

\author{
Ran Zhao, ${ }^{1}$ Shuang Xiao, ${ }^{2,3}$ Shihe Yang, ${ }^{2,3}$ and Xinwei Wang ${ }^{1, *}$
}

1. School of Advanced Materials, Shenzhen Graduate School, Peking University, Shenzhen 518055, China

2. Guangdong Key Lab of Nano-Micro Material Research, School of Chemical Biology and Biotechnology, Shenzhen Graduate School, Peking University, Shenzhen 518055, China

3. Department of Chemistry, The Hong Kong University of Science and Technology, Clear Water Bay, Kowloon, Hong Kong

*E-mail: wangxw@pkusz.edu.cn 
Table S1. Fitting results of the Ni 2 $p_{3 / 2}$ XPS spectra shown in Figure 1. (Bold font denotes the fixed parameters during fitting.)

\begin{tabular}{|c|c|c|c|c|c|c|c|c|c|c|c|c|c|c|c|c|c|c|}
\hline \multirow{4}{*}{$\begin{array}{c}\text { Temperature } \\
\left({ }^{\circ} \mathrm{C}\right)\end{array}$} & \multicolumn{18}{|c|}{$\mathrm{Ni} 2 \mathrm{p}_{3 / 2}$ signal } \\
\hline & \multicolumn{9}{|c|}{$\mathrm{Ni}-\mathrm{O}$} & \multicolumn{9}{|c|}{ Ni-metallic } \\
\hline & \multicolumn{3}{|c|}{ Main peak } & \multicolumn{3}{|c|}{ Satellite component 1} & \multicolumn{3}{|c|}{ Satellite component 2} & \multicolumn{3}{|c|}{ Main peak } & \multicolumn{3}{|c|}{ Satellite component 1} & \multicolumn{3}{|c|}{ Satellite component 2} \\
\hline & $\begin{array}{l}\mathrm{BE} \\
(\mathrm{eV})\end{array}$ & $\begin{array}{c}\text { Width } \\
(\mathrm{eV})\end{array}$ & $\begin{array}{l}\text { Area } \\
(\mathrm{cps} \\
\mathrm{eV})\end{array}$ & $\begin{array}{l}\mathrm{BE} \\
(\mathrm{eV})\end{array}$ & $\begin{array}{l}\text { Width } \\
(\mathrm{eV})\end{array}$ & $\begin{array}{l}\text { Area } \\
(\mathrm{cps} \\
\mathrm{eV})\end{array}$ & $\begin{array}{l}\mathrm{BE} \\
(\mathrm{eV})\end{array}$ & $\begin{array}{c}\text { Width } \\
(\mathrm{eV})\end{array}$ & $\begin{array}{c}\text { Area } \\
(\mathrm{cps} \mathrm{eV})\end{array}$ & $\begin{array}{l}\mathrm{BE} \\
(\mathrm{eV})\end{array}$ & $\begin{array}{l}\text { Width } \\
(\mathrm{eV})\end{array}$ & $\begin{array}{l}\text { Area } \\
(\mathrm{cps} \\
\mathrm{eV})\end{array}$ & $\begin{array}{c}\mathrm{BE} \\
(\mathrm{eV})\end{array}$ & $\begin{array}{l}\text { Width } \\
(\mathrm{eV})\end{array}$ & $\begin{array}{c}\text { Area } \\
(\mathrm{cps} \\
\mathrm{eV})\end{array}$ & $\begin{array}{c}\mathrm{BE} \\
(\mathrm{eV})\end{array}$ & $\begin{array}{l}\text { Width } \\
(\mathrm{eV})\end{array}$ & $\begin{array}{c}\text { Area } \\
(\mathrm{cps} \mathrm{eV})\end{array}$ \\
\hline $\mathrm{SiO}_{x} / \mathrm{Si}$ & - & - & - & - & - & - & - & - & - & - & - & - & - & - & - & - & - & - \\
\hline 25 & 856.5 & 3.1 & 17744.7 & 861.4 & 4.0 & 11103.5 & 865.1 & 4.0 & 5931.3 & - & - & - & - & - & - & - & - & - \\
\hline 100 & 856.5 & 3.1 & 19345.0 & 861.4 & 4.0 & 12150.1 & 865.1 & 4.0 & 6113.0 & - & - & - & - & - & - & - & - & - \\
\hline 150 & 856.7 & 3.1 & 20053.8 & 861.6 & 4.0 & 12633.9 & 865.3 & 4.0 & 6617.7 & 853.7 & 1.9 & 650.7 & 855.7 & 3.5 & 246.6 & 859.5 & 3.5 & 191.8 \\
\hline 200 & 856.8 & 3.1 & 19747.1 & 861.7 & 4.0 & 12440.6 & 865.4 & 4.0 & 6516.5 & 853.7 & 1.9 & 1321.2 & 855.7 & 3.5 & 458.9 & 859.5 & 3.5 & 389.4 \\
\hline 250 & 856.9 & 3.1 & 8762.1 & 861.8 & 4.0 & 5519.9 & 865.5 & 4.0 & 2891.5 & 853.7 & 1.9 & 9348.4 & 855.7 & 3.5 & 3084.7 & 859.5 & 3.5 & 2617.3 \\
\hline 300 & 857.0 & 3.1 & 3908.4 & 861.9 & 4.0 & 2462.3 & 865.6 & 4.0 & 1289.9 & 853.7 & 1.9 & 12463.8 & 855.7 & 3.5 & 4112.9 & 859.5 & 3.5 & 3489.9 \\
\hline 350 & 857.0 & 3.1 & 2079.1 & 861.9 & 4.0 & 1309.9 & 865.6 & 4.0 & 686.2 & 853.7 & 1.9 & 14139.3 & 855.7 & 3.5 & 4666.0 & 859.5 & 3.5 & 3959.0 \\
\hline 400 & 857.1 & 3.1 & 1530.9 & 862.0 & 4.0 & 964.5 & 865.7 & 4.0 & 505.2 & 853.7 & 1.9 & 14157.3 & 855.7 & 3.5 & 4671.9 & 859.5 & 3.5 & 3964.0 \\
\hline
\end{tabular}


Table S2. Fitting results of the O 1s XP spectra shown in Figure 2. (Bold font denotes the fixed parameters during fitting.)

\begin{tabular}{|c|c|c|c|c|c|c|}
\hline \multirow{3}{*}{$\begin{array}{c}\text { Temperature } \\
\left({ }^{\circ} \mathrm{C}\right)\end{array}$} & \multicolumn{6}{|c|}{ O 1s signal } \\
\hline & \multicolumn{3}{|c|}{$\mathrm{SiO}_{x}$} & \multicolumn{3}{|c|}{$\mathrm{Ni}-\mathrm{O}$} \\
\hline & $\begin{array}{l}\mathrm{BE} \\
(\mathrm{eV})\end{array}$ & $\begin{array}{l}\text { Width } \\
(\mathrm{eV})\end{array}$ & $\begin{array}{c}\text { Area } \\
(\mathrm{cpseV})\end{array}$ & $\begin{array}{l}\mathrm{BE} \\
(\mathrm{eV})\end{array}$ & $\begin{array}{c}\text { Width } \\
(\mathrm{eV})\end{array}$ & $\begin{array}{c}\text { Area } \\
(\mathrm{cps} \mathrm{eV})\end{array}$ \\
\hline $\mathrm{SiO}_{x} / \mathrm{Si}$ & 532.8 & 1.5 & 56466.8 & - & - & - \\
\hline 25 & 532.8 & 1.5 & 44862.9 & 530.9 & 1.5 & 1742.4 \\
\hline 100 & 532.8 & 1.5 & 45586.2 & 530.9 & 1.5 & 1836.4 \\
\hline 150 & 532.8 & 1.5 & 48351.5 & 530.9 & 1.5 & 1758.5 \\
\hline 200 & 532.8 & 1.5 & 50423.1 & 530.9 & 1.5 & 1524.1 \\
\hline 250 & 532.8 & 1.5 & 52947.8 & 530.9 & 1.5 & 1105.1 \\
\hline 300 & 532.8 & 1.5 & 53355.4 & 530.9 & 1.5 & 1183.6 \\
\hline 350 & 532.8 & 1.5 & 53802.4 & 530.9 & 1.5 & 897.6 \\
\hline 400 & 532.8 & 1.5 & 53831.8 & 530.9 & 1.5 & 860.9 \\
\hline
\end{tabular}


Table S3. Fitting results of the N 1s and C 1s XP spectra shown in Figure 3. (Bold font denotes the fixed parameters during fitting.)

\begin{tabular}{|c|c|c|c|c|c|c|c|c|c|c|c|c|c|c|c|c|c|c|}
\hline \multirow{4}{*}{$\begin{array}{c}\text { Temperature } \\
\left({ }^{\circ} \mathrm{C}\right)\end{array}$} & \multicolumn{6}{|c|}{$\mathrm{N}$ 1s signal } & \multicolumn{12}{|c|}{ C 1s signal } \\
\hline & \multirow{2}{*}{\multicolumn{3}{|c|}{$\mathrm{N}$ in $\mathrm{Ni}-$ amd }} & \multirow{2}{*}{\multicolumn{3}{|c|}{$\mathrm{N}$ in $-\mathrm{OH} \cdots$ Hamd }} & \multicolumn{9}{|c|}{ Carbon in amd } & \multirow{2}{*}{\multicolumn{3}{|c|}{ Additional carbon }} \\
\hline & & & & & & & \multicolumn{3}{|c|}{ Alkyl C } & \multicolumn{3}{|c|}{ Amido C } & \multicolumn{3}{|c|}{ Amidine $\mathrm{C}$} & & & \\
\hline & $\begin{array}{l}\mathrm{BE} \\
(\mathrm{eV})\end{array}$ & $\begin{array}{l}\text { Width } \\
(\mathrm{eV})\end{array}$ & $\begin{array}{l}\text { Area } \\
(\mathrm{cps} \\
\mathrm{eV}) \\
\end{array}$ & $\begin{array}{c}\mathrm{BE} \\
(\mathrm{eV})\end{array}$ & $\begin{array}{l}\text { Width } \\
(\mathrm{eV})\end{array}$ & $\begin{array}{l}\text { Area } \\
(\mathrm{cps} \\
\mathrm{eV}) \\
\end{array}$ & $\begin{array}{c}\mathrm{BE} \\
(\mathrm{eV})\end{array}$ & $\begin{array}{c}\text { Width } \\
(\mathrm{eV})\end{array}$ & $\begin{array}{l}\text { Area } \\
(\mathrm{cps} \\
\mathrm{eV}) \\
\end{array}$ & $\begin{array}{c}\mathrm{BE} \\
(\mathrm{eV})\end{array}$ & $\begin{array}{c}\text { Width } \\
(\mathrm{eV})\end{array}$ & $\begin{array}{c}\text { Area } \\
(\mathrm{cps} \\
\mathrm{eV})\end{array}$ & $\begin{array}{c}\mathrm{BE} \\
(\mathrm{eV})\end{array}$ & $\begin{array}{c}\text { Width } \\
(\mathrm{eV})\end{array}$ & $\begin{array}{l}\text { Area } \\
(\mathrm{cps} \\
\mathrm{eV})\end{array}$ & $\begin{array}{c}\mathrm{BE} \\
(\mathrm{eV})\end{array}$ & $\begin{array}{l}\text { Width } \\
(\mathrm{eV})\end{array}$ & $\begin{array}{c}\text { Area } \\
\text { (cps } \\
\mathrm{eV}) \\
\end{array}$ \\
\hline $\mathrm{SiO}_{x} / \mathrm{Si}$ & - & - & - & - & - & - & - & - & - & - & - & - & - & - & - & - & - & - \\
\hline 25 & 399.0 & 2.0 & 5216.3 & 400.9 & 2.0 & 826.8 & 285.5 & 1.7 & 15004.8 & 286.7 & 1.7 & 4291.3 & 287.5 & 1.7 & 2145.6 & - & - & - \\
\hline 100 & 399.2 & 2.0 & 5457.2 & 400.9 & 2.0 & 817.4 & 285.6 & 1.7 & 14467.5 & 286.8 & 1.7 & 4137.4 & 287.6 & 1.7 & 2069.0 & - & - & - \\
\hline 150 & 399.2 & 2.0 & 4839.7 & 400.9 & 2.0 & 540.6 & 285.5 & 1.7 & 10919.1 & 286.7 & 1.7 & 3122.8 & 287.5 & 1.7 & 1561.4 & - & - & - \\
\hline 200 & 399.3 & 2.0 & 4104.5 & 400.9 & 2.0 & 90.3 & 285.5 & 1.7 & 8191.9 & 286.7 & 1.7 & 2342.9 & 287.5 & 1.7 & 1171.4 & - & - & - \\
\hline 250 & 399.2 & 2.0 & 1256.1 & 400.9 & 2.0 & 62.4 & 285.5 & 1.7 & 2552.2 & 286.7 & 1.7 & 729.9 & 287.5 & 1.7 & 364.9 & 285.1 & 1.7 & 1408.4 \\
\hline 300 & 399.2 & 2.0 & 407.5 & 400.9 & 2.0 & 43.5 & 285.5 & 1.7 & 1008.4 & 286.7 & 1.7 & 288.4 & 287.5 & 1.7 & 144.2 & 285.1 & 1.7 & 2415.9 \\
\hline 350 & - & - & - & - & - & - & - & - & - & - & - & - & - & - & - & 285.0 & 1.7 & 3208.0 \\
\hline 400 & - & - & - & - & - & - & - & - & - & - & - & - & - & - & - & 284.9 & 1.7 & 2843.0 \\
\hline
\end{tabular}




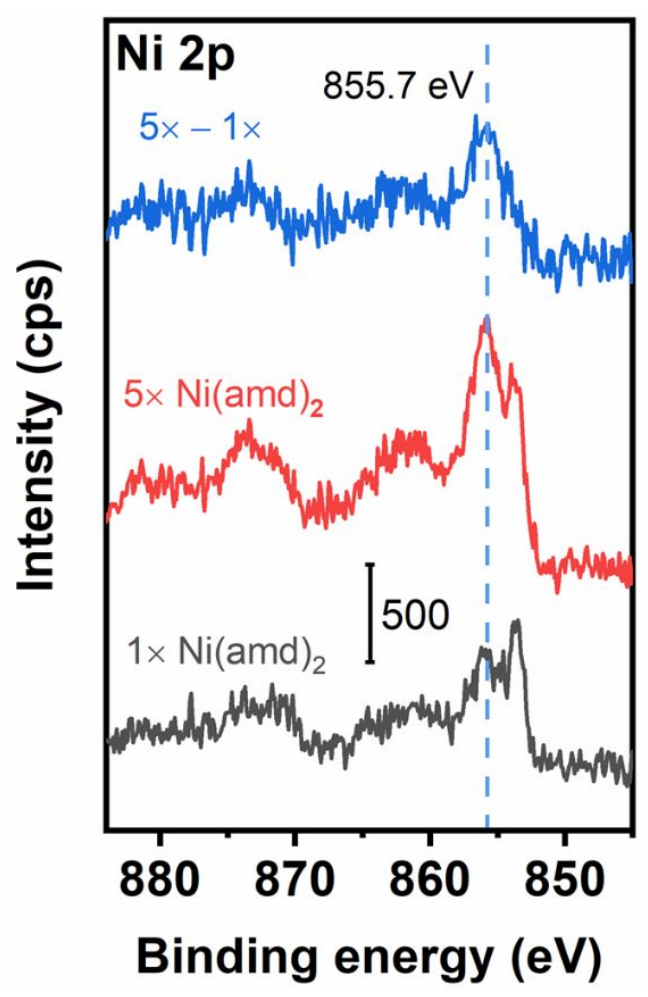

Figure S1. XPS Ni $2 p$ spectra for the Ni(amd $)_{2}$ dosed directly on HF-cleaned Si at room temperature. A regular $\mathrm{Ni}(\mathrm{amd})_{2}$ dose $(1 \times)$ and a 5 times larger dose $(5 \times)$ were used. The top trace shows the difference of the two spectra below. Since the Si surface inevitably contained some active dangling groups, the $\mathrm{Ni}(\mathrm{amd})_{2}$ molecules would first chemically react with these groups (chemisorption). But when excessive $\mathrm{Ni}(\text { amd })_{2}$ vapor was provided, molecular $\mathrm{Ni}(\text { amd })_{2}$ would eventually build up on the top (physisorption) at room temperature $\left(\mathrm{Ni}(\mathrm{amd})_{2}\right.$ is a solid at room temperature). Accordingly, the $5 \times-1 \times$ differential spectrum (blue color) should represent the spectrum of the physisorbed $\mathrm{Ni}(\text { amd })_{2}$, and therefore the $\mathrm{BE}$ of $\mathrm{Ni} 2 \mathrm{p}_{3 / 2}$ for molecular $\mathrm{Ni}(\text { amd })_{2}$ was found at $855.7 \mathrm{eV}$. 


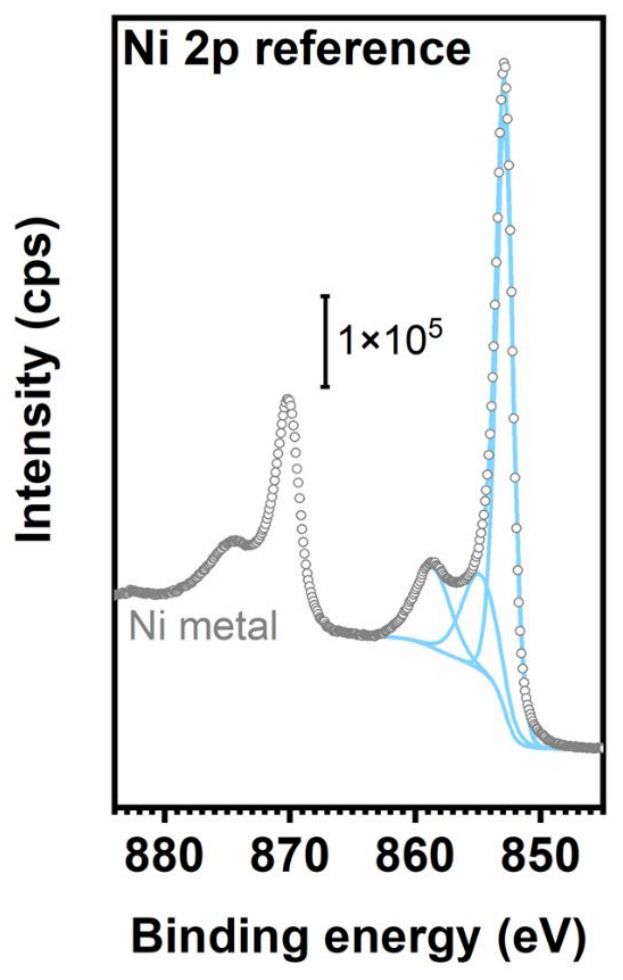

Figure S2. XPS Ni $2 p$ spectrum for bulk Ni metal. The Ni $2 p_{3 / 2}$ peak was fitted by using three peak components, of which one major component at $852.9 \mathrm{eV}$ was used to account for the main peak and two minor components at $854.9 \mathrm{eV}$ and $858.6 \mathrm{eV}$ were together used to account for the satellite band. 


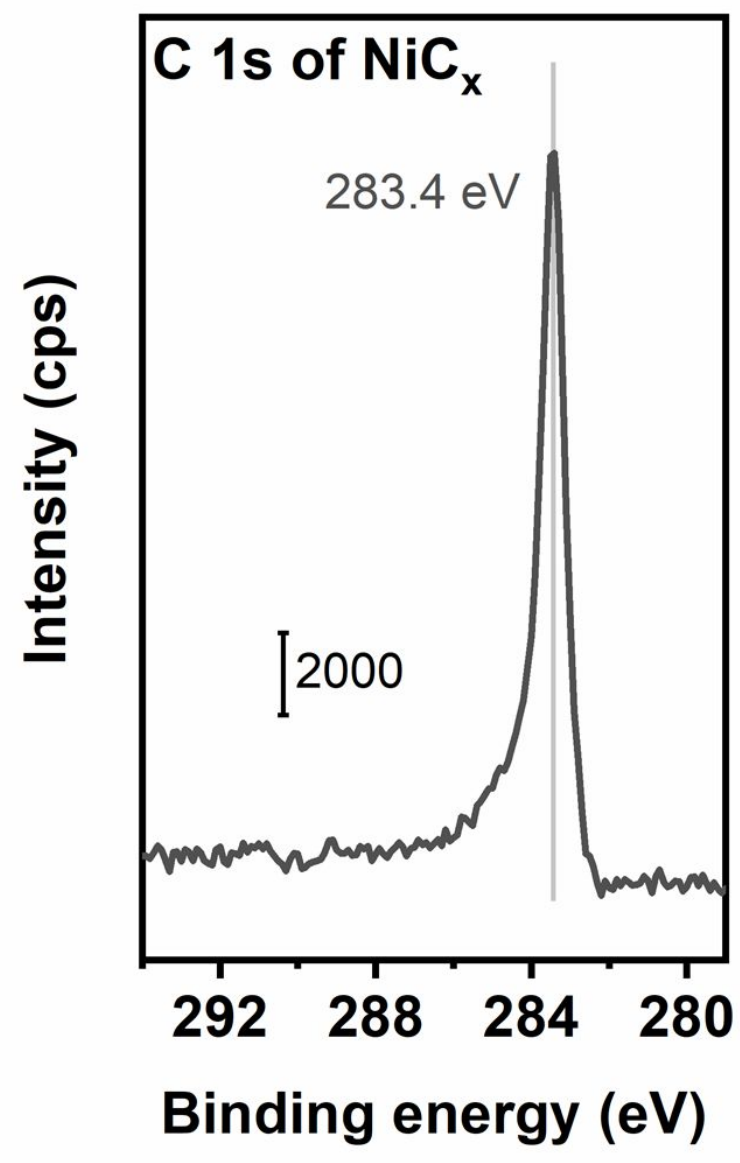

Figure S3. XPS C 1s spectrum for $\mathrm{NiC}_{\mathrm{x}}$, and the $\mathrm{BE}$ of the $\mathrm{C} 1 \mathrm{~s}$ peak is at $283.4 \mathrm{eV}$. The $\mathrm{NiC}_{\mathrm{x}}$ sample was prepared by ALD following the literature (ACS Appl. Mater. Interfaces, 2018, 10, 8384-8390). 
Table S4. Surface sensitivity factors for quantitative XPS analysis (Figure 5).

\begin{tabular}{c|c|c|c|c}
\hline \multicolumn{5}{c|}{ XPS signal } \\
\hline & Ni 2p & O 1s & N 1s & C 1s \\
\hline Binding energy $(e V)$ & 857 & 531 & 400 & 285 \\
Kinetic energy (eV) $(E)$ & 629 & 955 & 1086 & 1201 \\
\hline Bulk Sensitivity factor $\left(S_{\text {bulk }}\right)^{\mathrm{a}}$ & 20.76 & 2.89 & 1.68 & 1.00 \\
Surface Sensitivity factor $\left(S_{\text {surf }}\right)$ & 31.81 & 3.36 & 1.80 & 1.00 \\
\hline
\end{tabular}

aBulk sensitivity factors are adopted from Thermo Advantage (v5.945).

According to Wagner's paper on sensitivity factors (J. Electron Spectrosc. Relat.

Phenom. 1983, 32, 99-102), the surface sensitivity factors (rather than the conventional bulk sensitivity factors) should be used for the quantitative XPS analysis of the surface atoms. Note that the (bulk) sensitivity factors $\left(S_{\text {bulk }}\right)$ listed in common database (e.g. Thermo Advantage (v5.945)) are derived for bulk materials, which assumes that the material is of the thickness at least several times the length of the photoelectron mean free path $(\lambda)$; however, this is not applicable for surface adsorbates because the size of the adsorbates is usually smaller than $\lambda$. To this end, a new set of sensitivity factors, namely the surface sensitivity factors $\left(S_{\text {surf }}\right)$, should be used for the analysis of surface atoms. The set of $S_{\text {surf }}$ can be derived from that of $S_{\text {bulk }}$, following $S_{\text {surf }}=S_{\text {bulk }} / \lambda$, and the photoelectron mean free path $(\lambda)$ can be reasonably characterized by $\lambda=\alpha E^{0.66}$ (cf. Wagner's paper), where $E$ is the photoelectron kinetic energy. By adopting the normalization to give $S_{\text {surf }}(\mathrm{C} 1 \mathrm{~s})=1$, we arrive at $S_{\text {surf }}=S_{\text {bulk }}$ $\left(E_{\mathrm{C} 1 \mathrm{~s}} / E\right)^{0.66}$, which is used to calculate the $S_{\text {surf }}$ data shown in Table S4. 

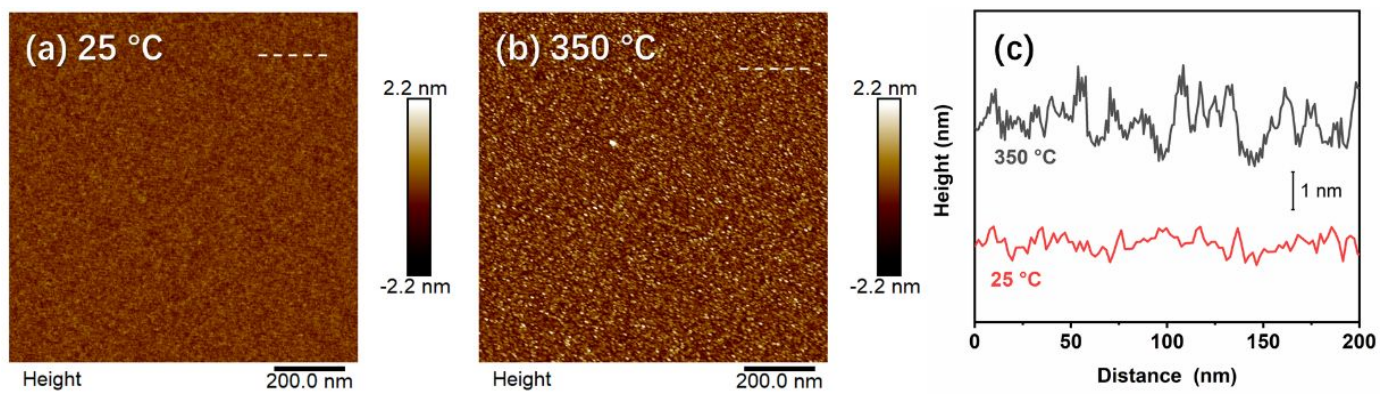

Figure S4. Ex situ atomic force microscopy (AFM, Bruker, Multimode 8) images of (a) a $\mathrm{Ni}(\text { amd })_{2}$-dosed $\mathrm{SiO}_{\mathrm{x}} / \mathrm{Si}$ sample and (b) a $\mathrm{Ni}(\text { amd })_{2}$-dosed $\mathrm{SiO}_{\mathrm{x}} / \mathrm{Si}$ sample subjected to the post-dose heat treatment at $350{ }^{\circ} \mathrm{C}$. In both cases, the $\mathrm{Ni}(\mathrm{amd})_{2}$ was dosed at $25{ }^{\circ} \mathrm{C}$. (c) Height profiles along the dashed lines drawn in (a) and (b). While the sample surface remained fairly flat after the $\mathrm{Ni}(\mathrm{amd})_{2}$ dose at $25{ }^{\circ} \mathrm{C}$, the $350{ }^{\circ} \mathrm{C}$ heat treatment substantially roughened the surface by creating nanoparticular features on the surface. The height profile (c) suggests that the size of the nanoparticles was about $1 \mathrm{~nm}$. It is worth noting that the lateral size of the nanoparticles was largely exaggerated in the AFM image because of the size of the AFM tip; nevertheless, the height information revealed from the AFM image should be accurate. 


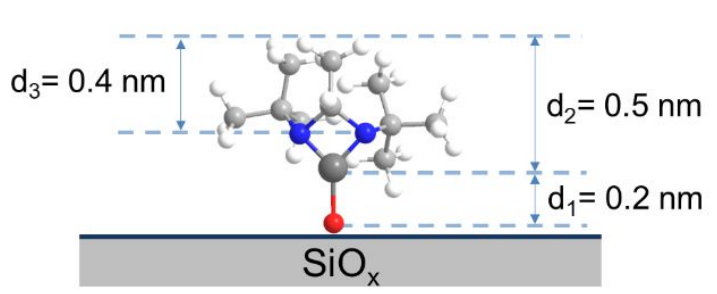

(a)

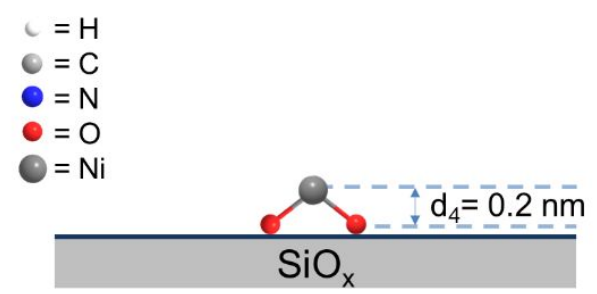

(b)

(c)

\begin{tabular}{c|c|c|c}
\hline \multicolumn{4}{c}{ Photoelectron mean free path $\lambda(\mathrm{nm})^{\mathrm{a}}$} \\
\hline & $\mathrm{Ni} 2 \mathrm{p}$ & $\mathrm{O} 1 \mathrm{~s}$ & $\mathrm{~N} 1 \mathrm{~s}$ \\
\hline in amidinate layer & $2.0\left(\lambda_{\mathrm{Ni}}\right)$ & $2.7\left(\lambda_{\mathrm{O} 2}\right)$ & $3.0\left(\lambda_{\mathrm{N}}\right)$ \\
in Ni layer & - & $1.5\left(\lambda_{\mathrm{O} 1}\right)$ & - \\
\hline
\end{tabular}

aData are adopted from the NIST database (Powell, C. J.; Jablonski, A. NIST Electron Inelastic-Mean-Free-Path Database, version 1.2, SRD 71; National Institute of Standards and Technology: Gaithersburg, MD, 2010).

bData of polystyrene are adopted to approximate the amidinate moiety.

Figure S5. Estimation of the XPS signal attenuation by the surface (a) $-\mathrm{O}-\mathrm{Ni}-$ amd (I) and (b) $\mathrm{O}-\mathrm{Ni}-\mathrm{O}$ (II) moieties.

It is well known that for a homogenous capping layer with uniform thickness of $d$, the measured (attenuated) XPS signal intensity ( $\left.I_{\text {meas }}\right)$ can be described by $I_{\text {meas }}=$ $I_{0} \exp (-d / \lambda)$, where $I_{0}$ is the intensity if there is no capping layer and $\lambda$ is the photoelectron mean free path in the capping layer. (The photoelectron takeoff angle is $90^{\circ}$.) Strictly speaking, $I_{0}$ should be used to quantify the surface atoms (such as Figure 5), however, because the "capping" layer is ill-defined in both structures (I) and (II), the attenuation effect cannot be treated rigorously. Therefore, we simply used $I_{\text {meas }}$ to quantify the surface atoms to obtain Figure 5. In the following, we will estimate the error that may be induced by using $I_{\text {meas }}$ for the quantitative analysis. 
We still adopt the general idea of the exponential decay $[\exp (-d / \lambda)]$ to describe the XPS signal attenuation, although some estimations are needed for $d$ 's and $\lambda$ 's. The estimations of $d$ 's are depicted in Figure S5a,b, where the d's describe the distances for which the photoelectrons generated on different atoms need to travel before entering into vacuum (for $d_{2 \sim 4}$ ) or another later (for $d_{1}$ ). The values of $\lambda$ 's (Figure S5c) are adopted from the NIST database for different photoelectron kinetic energies. Note that we use the data for polystyrene (a representative organic polymer) to approximate the amidinate moiety layer, because the latter does not exist in standard database. The detailed calculations are the following:

For the structure (I):

$$
\begin{aligned}
& I_{\text {meas }}(\mathrm{Ni}) / I_{0}(\mathrm{Ni})=\exp \left(-d_{2} / \lambda_{\mathrm{Ni}}\right)=\exp (-0.5 / 2.0)=0.778 \\
& I_{\text {meas }}(\mathrm{O}) / I_{0}(\mathrm{O})=\exp \left(-d_{2} / \lambda_{\mathrm{O} 2}\right) \exp \left(-d_{1} / \lambda_{\mathrm{O} 1}\right)=\exp (-0.5 / 2.7) \exp (-0.2 / 1.5)=0.727 \\
& I_{\text {meas }}(\mathrm{N}) / I_{0}(\mathrm{~N})=\exp \left(-d_{3} / \lambda_{\mathrm{N}}\right)=\exp (-0.4 / 3.0)=0.875
\end{aligned}
$$

Normalizing to the Ni intensity gives:

$$
\begin{aligned}
& \left.I_{\text {meas }}(\mathrm{O}) / I_{\text {meas }}(\mathrm{Ni})=0.934 I_{0}(\mathrm{O}) / I_{0}(\mathrm{Ni}) \quad \text { [i.e. } \sim 7 \% \text { underestimation }\right] \\
& \left.I_{\text {meas }}(\mathrm{N}) / I_{\text {meas }}(\mathrm{Ni})=1.125 I_{0}(\mathrm{~N}) / I_{0}(\mathrm{Ni}) \quad \text { [i.e. } \sim 12 \% \text { overestimation }\right]
\end{aligned}
$$

For the structure (II):

$$
\begin{aligned}
& I_{\text {meas }}(\mathrm{Ni}) / I_{0}(\mathrm{Ni})=1 \\
& I_{\text {meas }}(\mathrm{O}) / I_{0}(\mathrm{O})=\exp \left(-d_{4} / \lambda_{\mathrm{O} 1}\right)=\exp (-0.2 / 1.5)=0.875
\end{aligned}
$$

Normalizing to the Ni intensity gives:

$$
I_{\text {meas }}(\mathrm{O}) / I_{\text {meas }}(\mathrm{Ni})=0.875 I_{0}(\mathrm{O}) / I_{0}(\mathrm{Ni}) \quad[\text { i.e. } \sim 12 \% \text { underestimation }]
$$


Given the above calculation, we can conclude that using $I_{\text {meas }}$ for the quantitative XPS analysis would only cause slight underestimation of the $\mathrm{O}$ content $(7 \sim 12 \%)$ and slight overestimation of the $\mathrm{N}$ content (12\%). These small errors will not substantially alter the discussion and conclusions in the paper. Therefore, for simplicity with reasonable accuracy but not to make too many assumptions, we simply used $I_{\text {meas }}$ for the quantitative XPS analysis to obtain Figure 5. 


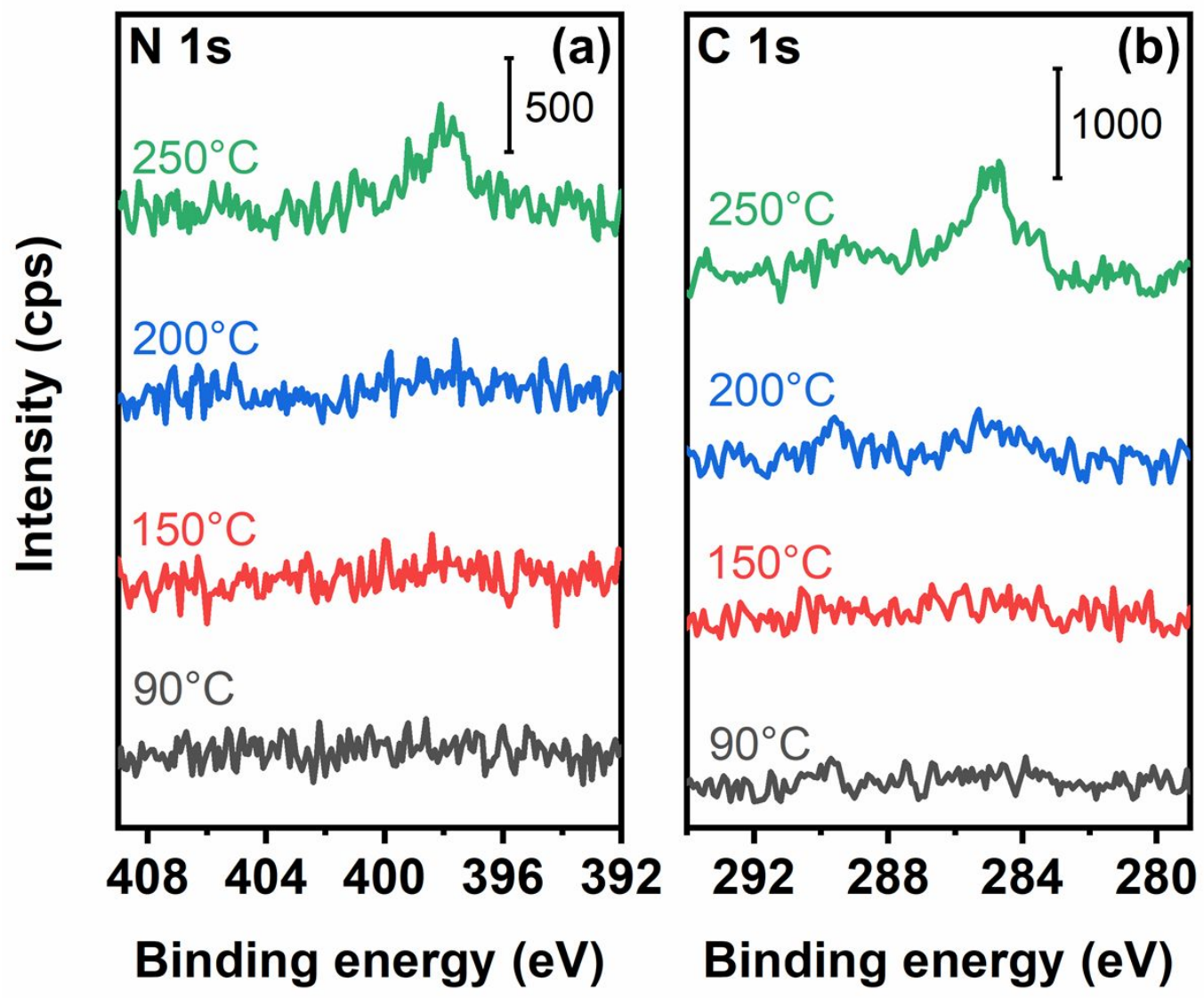

Figure S6. XPS N 1s and C 1s spectra for the ALD NiO films deposited at various temperatures. Drastic increase of the $\mathrm{C}$ and $\mathrm{N}$ contents can be seen for the temperature at $250{ }^{\circ} \mathrm{C}$. 